S. V. M. Hordern · J. E. Wright • A. M. Umpleby •

F. Shojaee-Moradie · J. Amiss $\cdot$ D. L. Russell-Jones

\title{
Comparison of the effects on glucose and lipid metabolism of equipotent doses of insulin detemir and NPH insulin with a 16-h euglycaemic clamp
}

Received: 20 July 2004 / Accepted: 18 November 2004 / Published online: 24 February 2005

(C) Springer-Verlag 2005

\begin{abstract}
Aims/hypothesis: The association of insulin detemir with non-esterified fatty acid binding sites on albumin may limit its transfer from the circulation into the extravascular extracellular space in adipose tissue and muscle, due to the capillary endothelial cell barrier. In the liver, the open sinusoids may expose hepatocytes to insulin detemir, enabling it to have a greater effect in the liver than in peripheral tissues. Methods: We investigated the effects of equipotent doses of insulin detemir and NPH insulin on hepatic glucose rate of appearance $\left(R_{\mathrm{a}}\right)$, peripheral glucose rate of disposal $\left(R_{\mathrm{d}}\right)$ and glycerol $R_{\mathrm{a}}$ (a measure of lipolysis) using stable isotope techniques. We also investigated the effects of these insulins on NEFA concentrations in seven healthy volunteers during a $16-\mathrm{h}$ euglycaemic clamp. A higher dose of insulin detemir was also studied. Results: There was no difference in the glucose infusion profile between insulin detemir and NPH. Insulin detemir had a greater effect on mean suppression of glucose $R_{\mathrm{a}}$ (mean difference $0.24 \mathrm{mg} \mathrm{kg}^{-1} \mathrm{~min}^{-1}$; CI 0.09 $0.39 ; p<0.01$ ), and minimum glucose $R_{\mathrm{a}}$, with minimum low dose detemir $-0.10 \pm 0.15 \mathrm{mg} \cdot \mathrm{kg}^{-1} \cdot \mathrm{min}^{-1}$ and minimum NPH $0.17 \pm 0.10 \mathrm{mg} \cdot \mathrm{kg}^{-1} \cdot \mathrm{min}^{-1}(p<0.02)$. However, it had a lesser effect on mean suppression of NEFA concentrations (mean difference $-0.10 \mathrm{mmol} / \mathrm{l}$; CI -0.03 to -0.17 ; ANOVA, $p<0.02)$ than NPH. The effect of insulin
\end{abstract}

S. V. M. Hordern · J. E. Wright · J. Amiss

D. L. Russell-Jones

Department of Diabetes and Endocrinology,

Post Graduate Medical School, University of Surrey,

Guildford, Surrey, UK

A. M. Umpleby · F. Shojaee-Moradie

Department of Diabetes and Endocrinology,

GKT School of Medicine, Kings College,

London, UK

D. L. Russell-Jones $(\bowtie)$

Department of Diabetes and Endocrinology,

Royal Surrey Hospital,

Guildford, Surrey, UK

e-mail: drj@royalsurrey.nhs.uk

Tel.: +1-483-571122

Fax: +1-483-406839 detemir on glucose $R_{\mathrm{d}}$ and glycerol $R_{\mathrm{a}}$ was not different from NPH. Following high-dose detemir, total glucose infused and maximum glucose $R_{\mathrm{d}}$ were higher $(p<0.02, p<0.03)$ and plasma NEFA concentrations lower $(p<0.01)$ than with low-dose determir. Conclusions/interpretation: This study suggests that insulin detemir, when compared to NPH insulin, has a greater effect on the liver than on peripheral tissues and thus has the potential to restore the physiological insulin gradient.

Keywords Detemir - Glucose · Insulin · Metabolism • $\mathrm{NPH}$ insulin

Abbreviations $C_{\max }$ : Maximum concentration - GIR: Glucose infusion rate $\cdot$ HD: High-dose detemir - LD: Low-dose detemir - NPH: Neutral protamine Hagedorn · $R_{\mathrm{a}}$ : Rate of appearance $\cdot R_{\mathrm{d}}$ : Rate of disposal $\cdot V_{\max }$ : Maximum velocity

\section{Introduction}

Conventional basal long-acting insulins are prepared using protamine or zinc to form slowly dissolving crystals. Absorption rates of these preparations fluctuate from day to day influenced by many variables [1-3]. Inhomogeneities in the suspension result in different amounts of insulin being injected [4]. Insulin detemir was designed to overcome the problems of crystalline long-acting insulin by being soluble both before and after injection, its action being prolonged by albumin binding and self association at the injection site [5].

Some would argue that current insulin replacement regimens have an additional disadvantage. In normal physiology, insulin is released from the pancreas into the portal circulation exerting direct effects on the liver. In this 'first pass' the liver extracts up to $60 \%$ of the insulin delivered to it, the remainder is dispersed into the systemic circulation. In consequence, hepatocytes are exposed to insulin concentrations three to four times higher than the other target organs for insulin, namely adipose tissue and mus- 
cle. Pharmacologically, insulin is delivered into a subcutaneous depot and absorbed into the systemic circulation through which it is distributed in approximately equal concentrations throughout the body. The normal portal/peripheral insulin gradient is lost, resulting in relative peripheral hyperinsulinaemia and underinsulinisation of the liver. Some authors have suggested that this relative underinsulinisation of the liver may play an important role in the development of microvascular complications [6-9].

Insulin detemir is a long-acting soluble insulin analogue, with a 14-carbon fatty acid chain attached to position B29 and omission of the amino acid residue at position B30 of the human insulin molecule [10]. The fatty acid residue associates with free fatty acid binding sites on albumin in interstitial fluid and plasma [11], developing an equilibrium between free and albumin-bound analogue. Only the free fraction of insulin detemir permeates the capillary wall, entering the blood stream and binding to albumin again. To reach peripheral target tissues (muscle and adipose) free insulin detemir must again pass the capillary wall. The principle of protraction is based on slow release from albumin and strong self-association at the injection site $[5,10]$.

Capillary endothelial cells in adipose tissue and muscle limit the transfer of insulin detemir from the circulation into the extravascular extracellular space [5], whereas in the liver the sinusoids are lined by highly fenestrated epithelial cells, between which there are large gaps. The sinusoids also have no basal lamina. Because of the large gaps in the endothelial cell layer and the absence of a continuous basal lamina, no significant barrier exists between blood plasma in the sinusoid and the hepatocyte plasma membrane [12]. Both free and albumin-bound insulin detemir can therefore pass freely to this 'space of Disse' (the perisinusoidal space) $[13,14]$. Hepatocytes will thus be freely exposed to insulin detemir, possibly resulting in a greater effect of this insulin analogue on the liver than on peripheral tissue.

We have investigated the effects of insulin detemir (9 $\mathrm{nmol} / \mathrm{kg}$ ) and an equipotent dose of NPH insulin (1.8 $\mathrm{nmol} / \mathrm{kg})$ on hepatic glucose output $\left(R_{\mathrm{a}}\right)$, peripheral glucose uptake $\left(R_{\mathrm{d}}\right)$ and glycerol $R_{\mathrm{a}}$ using stable isotope techniques. We also investigated the effects of these substances on NEFA concentrations in healthy subjects during a 16 -h euglycaemic clamp. The effect of the $18 \mathrm{nmol} / \mathrm{kg}$ dose of detemir is also described and analysed.

\section{Subjects, materials and methods}

Volunteers Sample size calculation was based on the peripheral glucose uptake in a two-period, two-treatment subdesign of the three periods. The intrasubject coefficient of variation was assumed to be $25 \%$ maximum. Considering a relative difference of $50 \%$, and using a significance level of $5 \%$, the power would be $85 \%$ if eight subjects completed the trial and $70 \%$ if six subjects completed the trial. Based on this sample size calculation, eight subjects were included in the trial. If more than two subjects were withdrawn, replacement subjects were to be enrolled in order to ensure that at least six subjects completed the trial in each group. Volunteers gave written informed consent. The South West Surrey ethics committee approved the study.

Experimental protocol Following screening, volunteers were assigned the lowest available randomisation number and randomised to a specific treatment sequence in a randomised block design that was unknown to the investigator until the day before each study. The study was not blinded. Volunteers were studied on three separate occasions 7-28 days apart. Volunteers received (1) detemir 9 $\mathrm{nmol} / \mathrm{kg}$ (low-dose detemir [LD]), (2) detemir $18 \mathrm{nmol} / \mathrm{kg}$ (high-dose detemir [HD]) or (3) human NPH insulin 0.3 $\mathrm{IU} / \mathrm{kg}(1.8 \mathrm{nmol} / \mathrm{kg})(\mathrm{NPH})$ (Novo-Nordisk) in random order. Following an overnight fast they remained fasting and in a supine or semisupine position for the entire study. Two intravenous cannulae were inserted (one each for blood sampling and administration of the various infusates). Following baseline blood sampling, a priming dose of $170 \mathrm{mg}$ $\left[6,6-{ }^{2} \mathrm{H}_{2}\right]$ glucose and $0.14 \mathrm{mg} / \mathrm{kg}\left[1,1,2,3,3-{ }^{2} \mathrm{H}_{5}\right]$ glycerol (both $99 \%$ enrichment, sterile and pyrogen-free; Phenome Sciences, Woburn, MA, USA) was given followed by a continuous infusion of $102 \mathrm{mg} / \mathrm{h}\left[6,6-{ }^{2} \mathrm{H}_{2}\right]$ glucose and 0.5 $\mathrm{mg} \mathrm{kg}^{-1} \mathrm{~h}^{-1}\left[1,1,2,3,3{ }^{2} \mathrm{H}_{5}\right]$ glycerol from -150 to $960 \mathrm{~min}$. After a 120-min equilibration period to reach steady state, tracer enrichment samples were taken between -30 min and time 0 to measure glucose and glycerol enrichment and concentration. At time 0 subjects received a subcutaneous injection of insulin according to randomisation. Blood samples were taken every $15 \mathrm{~min}$ for the measurement of plasma glucose. The glucose infusion rate (GIR) of $20 \%$ dextrose (containing $4 \mathrm{mg} / \mathrm{g}\left[6,6{ }^{2} \mathrm{H}_{2}\right]$ glucose) was adjusted to clamp the blood glucose to their presenting blood glucose level on the first study day. The aim was to clamp blood glucose between 4.0 and $5.5 \mathrm{mmol} / \mathrm{l}$ for $960 \mathrm{~min}$ after the subcutaneous injection. Blood was regularly sampled for the measurement of plasma glucose and glycerol enrichment and concentration and plasma NEFA and insulin concentrations. The insulin detemir preparation available for use in this study was $1200 \mathrm{nmol} / \mathrm{ml}$ (currently used preparations of detemir contain $2400 \mathrm{nmol} / \mathrm{ml})$.

Analytical procedures Plasma glucose was measured using a YSI 2300 (Yellow Springs Instruments, Columbus, OH, USA). Glucose and glycerol enrichment was determined by gas chromatography-mass spectrometry on an MSD 5971 A (Hewlett-Packard, Woking, UK) using selected ion monitoring of a methoxime trimethylsilyl ether derivative [15] and the tert-butyltrimethylsilyl glycerol derivative [16]. NEFA and glycerol concentrations were measured on a Cobas Fara II (Roche, Welwyn Garden City, UK) using a WAKO NEFA C (Wako Chemicals, Neuss, Germany; interassay CV 3.6\%) and a Randox glycerol kit (Randox Laboratories, Co Antrim, UK; interassay CV 3.7\%). Insulin detemir was measured using an ELISA-specific insulin detemir assay, which measures total concentrations of insulin detemir (both free and bound) [17]. Human insulin 
was measured using the DAKO insulin ELISA assay (interassay CV 4.2-9.3\%). C peptide was measured using the DAKO C-peptide ELISA assay (interassay CV 3.3$5.7 \%$ ).

Calculations Glucose $R_{\mathrm{a}}$ and $R_{\mathrm{d}}$ were calculated using a modified form of the Steele equation [18] adapted by Finegood et al. [19] to account for the addition of stable labelled tracer to the exogenous glucose infusate. We used a volume of distribution of $220 \mathrm{ml} / \mathrm{kg}$ and an effective glucose: actual space of 0.65 . Glycerol $R_{\mathrm{a}}$ was also calculated using the Steele equation (volume of distribution= $230 \mathrm{ml} / \mathrm{kg}$ ). Changes in glucose $R_{\mathrm{a}}$ and $R_{\mathrm{d}}$, expressed as a percentage of GIR at each time point, were averaged over 960 min to determine which proportion of the glucose lowering effect of each insulin was due to a decrease in $R_{\mathrm{a}}$ and which proportion was due to an increase in $R_{\mathrm{d}}$. All values are expressed as means \pm SEM. Mean values for minimum and maximum effect are calculated using the minimum or maximum point in the set of data for each individual. Statistical analysis of the results was by a twoway analysis of covariance using baseline as a covariate and by a paired Student's $t$-test, with $p$ values less than 0.05 being considered statistically significant.

\section{Results}

Eight volunteers were randomised following screening for the study. Seven healthy adults (three women, four men; age $29.9 \pm 3.7$ years; BMI $22.9 \pm 0.8 \mathrm{~kg} / \mathrm{m}^{2} ; 68.0 \pm 2.9 \mathrm{~kg}$ ) completed three studies. One volunteer performed the NPH study day, but did not undergo further studies. The results from this NPH study were therefore not paired and have not been included in our analysis. One of the volunteers who completed all study days was not fasting on the day of the HD $(18 \mathrm{nmol} / \mathrm{kg})$ insulin detemir, the results for that HD study have been excluded. The results presented for the LD and NPH trials are for seven subjects, results for the HD study are for six subjects only.
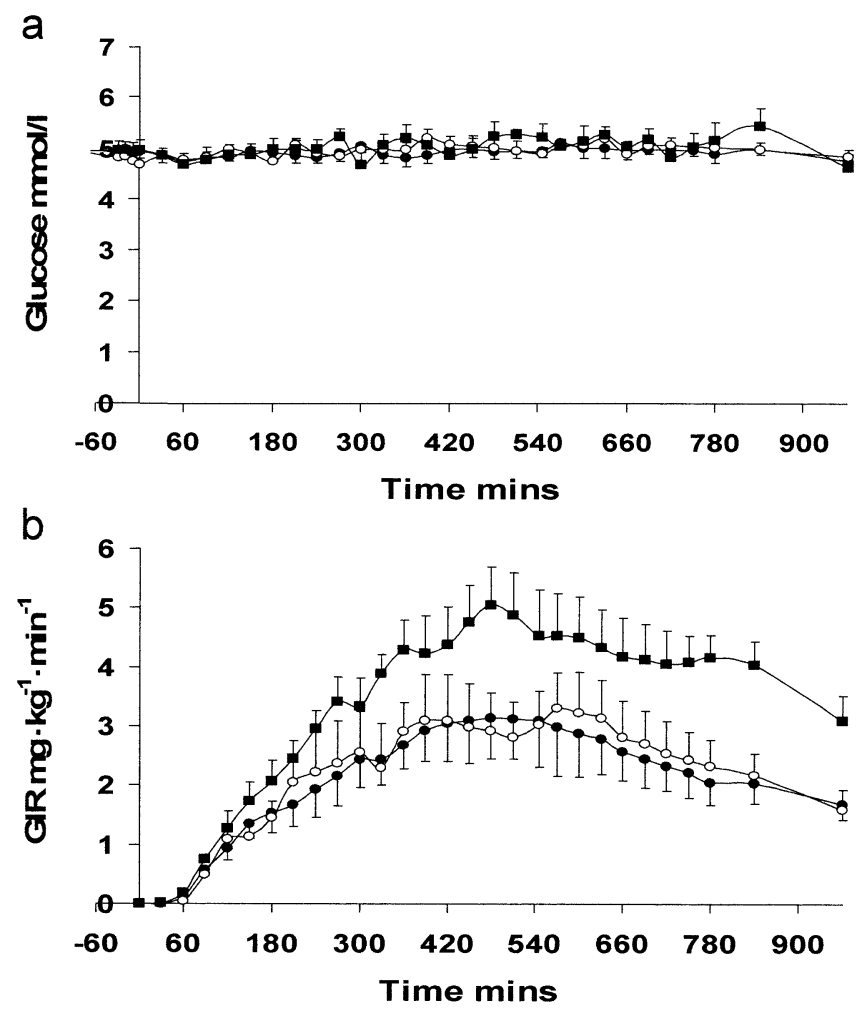

Fig. 1 Plasma glucose concentrations (a), during euglycaemic clamp studies in healthy volunteers. High-dose insulin detemir (HD), black squares; low-dose insulin detemir $(L D)$, black circles; NPH insulin $(N P H)$, white circles. Glucose infusion rate $(G I R)(\mathbf{b})$. HD, black squares; LD, black circles; NPH, white circles

Plasma glucose These results are presented in Table 1 and Fig. 1a. Euglycaemia was maintained throughout all clamp studies. Mean plasma glucose was clamped at $4.92 \pm 0.11$, $4.95 \pm 0.08$ and $5.01 \pm 0.14 \mathrm{mmol} / 1$ in the LD, NPH and HD studies, respectively (these values were not statistically different). The mean and standard difference of the individual coefficient of variation for glucose during the clamp studies was $4.95 \pm 1.82 \%$ for LD, $6.32 \pm 2.34 \%$ for NPH and $7.82 \pm 3.76 \%$ for HD.

Table 1 The effect of low-dose detemir and NPH on glucose metabolism

\begin{tabular}{lccc}
\hline & Low-dose detemir & NPH insulin & Mean difference (CI) \\
\hline Plasma glucose $(\mathrm{mmol} / \mathrm{l})$ & $4.92 \pm 0.11$ & $4.95 \pm 0.08$ & $0.03(-0.22$ to 0.25$)$ \\
Total amount of glucose infused $(\mathrm{mg})$ & $2019 \pm 374$ & $2102 \pm 384$ & $74.4(-487$ to 636$)$ \\
Time to start of glucose infusion $(\mathrm{min})$ & $60.9 \pm 9.5$ & $63.7 \pm 7.2$ & $2.86(-24.2$ to 29.9$)$ \\
Peak glucose infusion rate $\left(\mathrm{mg} \cdot \mathrm{kg}^{-1} \cdot \mathrm{min}^{-1}\right)$ & $3.68 \pm 0.72$ & $4.04 \pm 0.73$ & $0.35(-0.74$ to 1.44$)$ \\
Glucose infusion rate at $960 \mathrm{~min}\left(\mathrm{mg} \cdot \mathrm{kg}^{-1} \cdot \mathrm{min}^{-1}\right)$ & $1.64 \pm 0.23$ & $1.42 \pm 0.15$ & $-0.22(-0.86$ to 0.42$)$ \\
Baseline glucose $R_{\mathrm{a}}\left(\mathrm{mg} \cdot \mathrm{kg}^{-1} \cdot \mathrm{min}^{-1}\right)$ & $2.01 \pm 0.12$ & $2.17 \pm 0.09$ & $0.17(-0.05$ to 0.39$)$ \\
Minimum glucose $R_{\mathrm{a}}\left(\mathrm{mg} \cdot \mathrm{kg}^{-1} \cdot \mathrm{min}^{-1}\right)$ & $-0.10 \pm 0.15$ & $0.17 \pm 0.10$ & $0.27(0.09-0.45)$ \\
Mean glucose $R_{\mathrm{a}}\left(\mathrm{mg} \cdot \mathrm{kg} \cdot \mathrm{min}^{-1}\right)$ & $0.69 \pm 0.12$ & $0.93 \pm 0.09$ & $0.24(0.09-0.39)$ \\
Baseline glucose $R_{\mathrm{d}}\left(\mathrm{mg} \cdot \mathrm{kg}^{-1} \cdot \mathrm{min}^{-1}\right)$ & $2.06 \pm 0.12$ & $2.18 \pm 0.08$ & $0.13(-0.14$ to 0.40) \\
Maximum glucose $R_{\mathrm{d}}\left(\mathrm{mg} \cdot \mathrm{kg}^{-1} \cdot \mathrm{min}^{-1}\right)$ & $3.58 \pm 0.54$ & $4.15 \pm 0.58$ & $0.6(-0.35$ to 1.55$)$ \\
Mean glucose $R_{\mathrm{d}}\left(\mathrm{mg} \cdot \mathrm{kg} \cdot \mathrm{min}^{-1}\right)$ & $2.64 \pm 0.30$ & $2.96 \pm 0.32$ & $0.33(-0.15$ to 0.80$)$ \\
\hline
\end{tabular}

Values are means \pm SEM 


\section{ind}

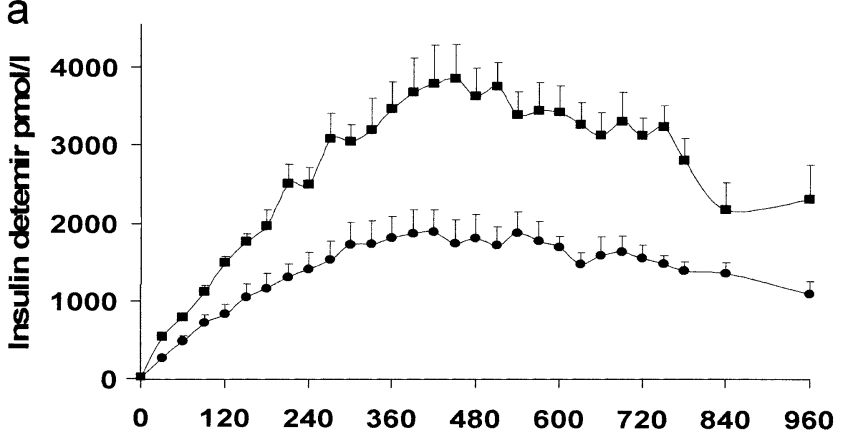

Time mins

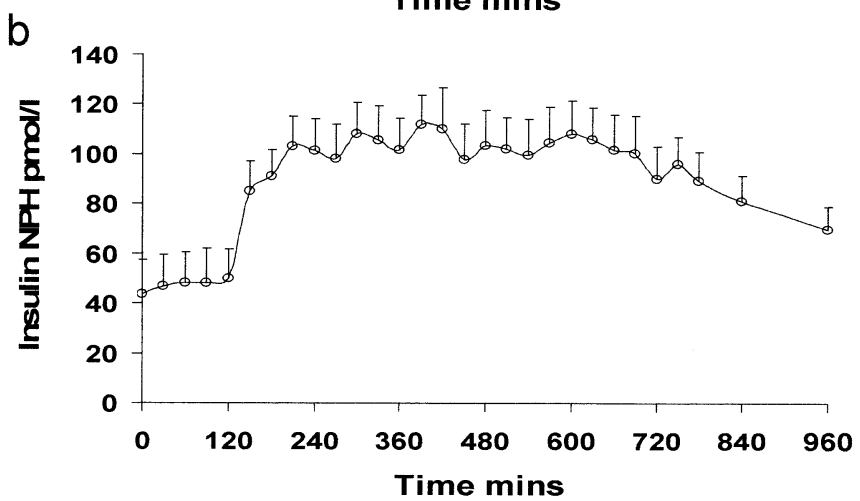

Fig. 2 Plasma insulin detemir concentrations (a), during euglycaemic clamp studies in healthy volunteers. High-dose insulin detemir, black squares; low-dose insulin detemir, black circles. Plasma human insulin concentration (b). NPH insulin, white circles

Insulin Figure 2a and $\mathrm{b}$ show that mean AUC (0-960 min) was $1350.8 \pm 125.8,2220.4 \pm 417.5$ and $81.4 \pm 11.7 \mathrm{nmol} / 1$ min for LD, HD and NPH, respectively. There was no individual difference in the time to reach maximum concentration, which for the three insulins was $617 \pm 85,520 \pm$ 79 and $420 \pm 60$ min for LD, HD and NPH, respectively. The maximum concentration $\left(C_{\max }\right)$ was greater for HD $(4478 \pm 190 \mathrm{pmol} / \mathrm{l})$ than for $\mathrm{LD}(2345 \pm 222 \mathrm{pmol} / \mathrm{l}, p<0.01)$. $C_{\max }$ for NPH was $122 \pm 14 \mathrm{pmol} / \mathrm{l}$.

C-Peptide C-Peptide (Fig. 3) at baseline was similar in each insulin study, being $0.47 \pm 0.04,0.55 \pm 0.08$ and $0.31 \pm$ $0.13 \mathrm{nmol} / \mathrm{l}$ for LD, NPH and HD, respectively. C-Peptide was suppressed following each insulin, and there was no difference in this suppression between the insulins with minimum C-peptide values of $0.25 \pm 0.05,0.27 \pm 0.05$ and $0.15 \pm 0.06 \mathrm{nmol} / \mathrm{l}$ following $\mathrm{LD}, \mathrm{NPH}$ and $\mathrm{HD}$, respectively.

Glucose metabolism following low-dose detemir and NPH The total amount of glucose infused to maintain euglycaemia was similar for LD $(2019 \pm 374 \mathrm{mg} / \mathrm{kg})$ and NPH $(2102 \pm 384 \mathrm{mg} / \mathrm{kg})(p=\mathrm{NS})$, demonstrating the equipotency of the doses of these two insulins (Fig. 1b). There was no difference between LD and NPH in the time to starting the glucose infusion, peak glucose infusion rate or glucose infusion rate at $960 \mathrm{~min}$.

Minimum glucose $R_{\mathrm{a}}$ was significantly lower $(p<0.02)$ with $\mathrm{LD}\left(-0.10 \pm 0.15 \mathrm{mg} \mathrm{kg}^{-1} \mathrm{~min}^{-1}\right)$ than with NPH $(0.17 \pm$

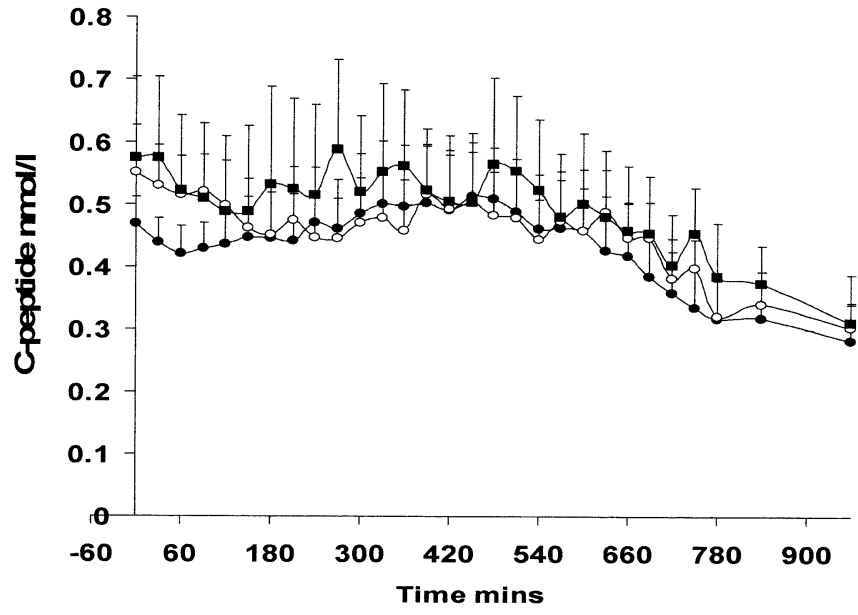

Fig. 3 C-Peptide concentrations (a), during euglycaemic clamp studies in healthy volunteers. High-dose insulin detemir, black squares; low-dose insulin detemir, black circles; NPH insulin, white circles. Hepatic glucose output $\left(R_{\mathrm{a}}\right)$

$0.10 \mathrm{mg} \mathrm{kg}^{-1} \mathrm{~min}^{-1}$ ) (Fig. 4b). Using ANOVA, glucose $R_{\mathrm{a}}$ with LD was significantly lower than with NPH (mean difference $0.24 \mathrm{mg} \mathrm{kg}^{-1} \mathrm{~min}^{-1}$; CI $\left.0.09-0.39 ; p<0.01\right)$. This difference was still significant $(p<0.05)$ when corrected for baseline (mean difference $0.25 \mathrm{mg} \mathrm{kg}^{-1} \mathrm{~min}^{-1}$; CI $0.05-$ 0.44 ) using analysis of covariance. Although the maximum change from baseline of glucose $R_{\mathrm{d}}$ (for each individual) appeared to be lower with LD $\left(1.52 \pm 0.49 \mathrm{mg} \mathrm{kg}^{-1} \mathrm{~min}^{-1}\right)$
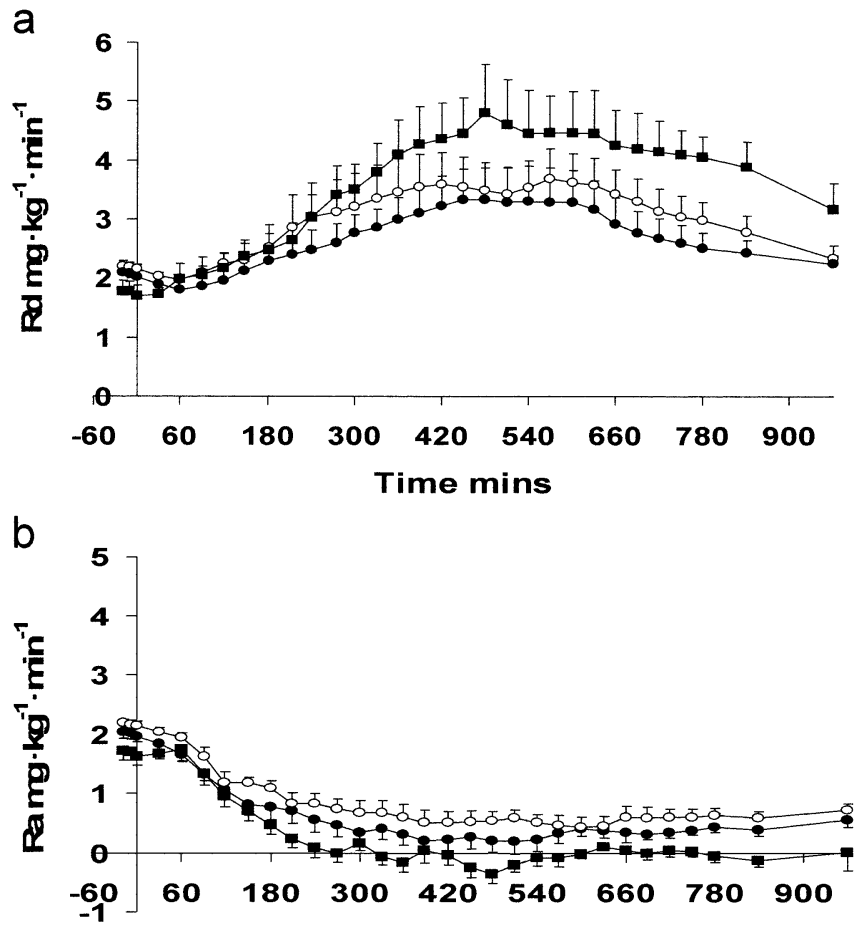

Time mins

Fig. 4 Peripheral glucose uptake $\left(R_{\mathrm{d}}\right)(\mathbf{a})$, during euglycaemic clamp studies in healthy volunteers. High-dose insulin detemir, black squares; low-dose insulin detemir, black circles; NPH insulin, white circles. Hepatic glucose output $\left(R_{\mathrm{a}}\right)(\mathbf{b})$. HD, black squares; LD, black circles; NPH insulin, white circles 


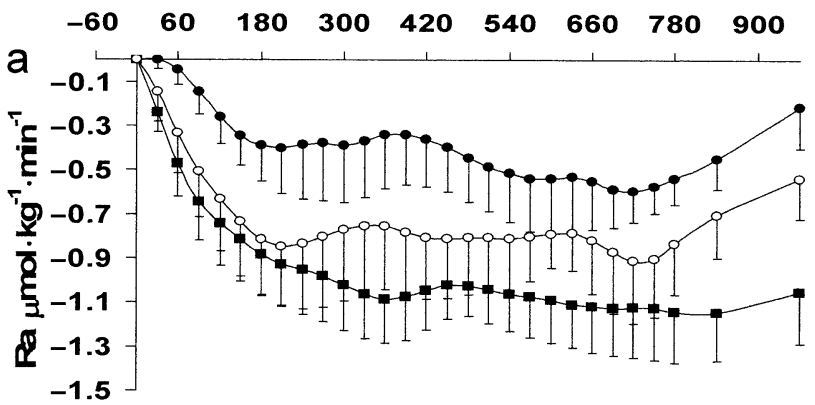

Time mins

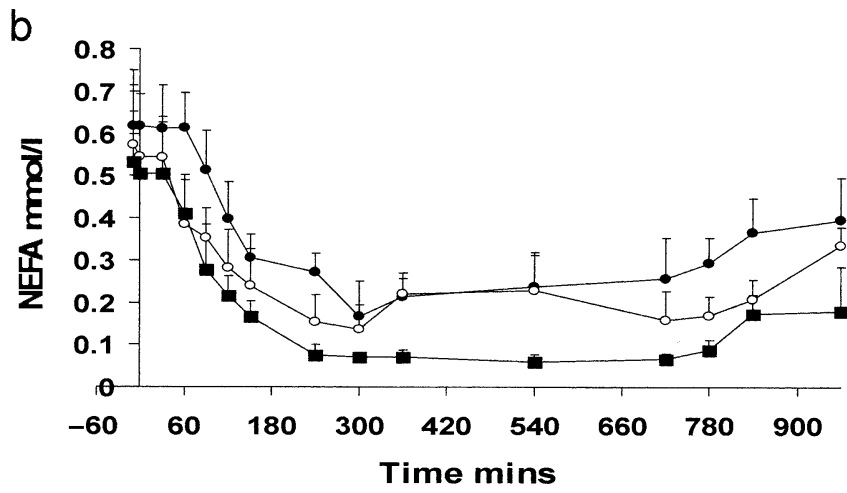

Fig. 5 Glycerol rate of appearance $\left(R_{\mathrm{a}}\right)(\mathbf{a})$, change from baseline during euglycaemic clamp studies in healthy volunteers. High-dose insulin detemir, black squares; low-dose insulin detemir, black circles; NPH insulin, white circles. Plasma NEFA concentrations (b). High-dose insulin detemir, black squares; low-dose insulin detemir, black circles; NPH insulin, white circles

than NPH $\left(1.97 \pm 0.52 \mathrm{mg} \mathrm{kg}^{-1} \mathrm{~min}^{-1}\right)$, this change was not statistically significant $(p=0.2)$ (Fig. $4 \mathrm{a})$. Of the mean glucose lowering effect of low-dose insulin detemir over the 960 min (the proportion of infused glucose needed to overcome each of $R_{\mathrm{a}}$ and $R_{\mathrm{d}}$ ), $71.3 \pm 4 \%$ was due to the decrease in $R_{\mathrm{a}}$ and $28.7 \pm 4 \%$ was due to the increase in glucose $R_{\mathrm{d}}$. The corresponding values for NPH were $63.3 \pm$ $3.9 \%$ and $36.7 \pm 3.9 \%$, respectively $(p<0.01)$.

Glycerol metabolism (Fig. 5a) and NEFA concentration (Fig. 5b) following LD and NPH (Table 2) There appeared to be less suppression of glycerol $R_{\mathrm{a}}$ with LD than NPH, but these differences were not found to be significant statistically. The maximum change from baseline for glycerol $R_{\mathrm{a}}$ was $-0.82 \pm 0.17 \mu \mathrm{mol} \mathrm{kg} \mathrm{min}^{-1}$ with $\mathrm{LD}$, and $-1.10 \pm$ $0.24 \mu \mathrm{mol} \mathrm{kg}{ }^{-1} \mathrm{~min}^{-1}$ with NPH $(p=0.2)$. The baseline plasma NEFA concentration was $0.65 \pm 0.08$ and $0.52 \pm$ $0.11 \mathrm{mmol} / \mathrm{l}$ for LD and NPH, respectively $(p=\mathrm{NS})$. There was significantly more suppression of NEFA concentration with NPH than with LD (mean difference $-0.10 \mathrm{mmol} / \mathrm{l}$; CI -0.03 to -0.17 ; ANOVA, $p<0.02)$. Minimum NEFA concentrations following LD $(0.12 \pm 0.04 \mathrm{mmol} / \mathrm{l})$ or $\mathrm{NPH}$ $(0.09 \pm 0.03 \mathrm{mmol} / \mathrm{l})$ were not significantly different.

Glucose, glycerol and NEFA metabolism following HD (Figs. 1b, 4a, b, 5a, b)

The glucose infusion started earlier following HD (40 \pm $7.5 \mathrm{~min})$ than LD $(61 \pm 9.6 \mathrm{~min}, p<0.03)$. Peak GIR was higher following HD $\left(5.7 \pm 0.82 \mathrm{mg} \mathrm{kg} \mathrm{min}^{-1}\right)$ than LD (3.68 $\left.\pm 0.72 \mathrm{mg} \mathrm{kg}^{-1} \mathrm{~min}^{-1}, p<0.03\right)$. Total glucose infused was significantly higher following HD $(3267 \pm 388 \mathrm{mg} / \mathrm{kg})$ than LD $(p<0.02)$. Baseline glucose $R_{\mathrm{a}}$ and $R_{\mathrm{d}}$ were similar for HD compared to NPH and LD (being $1.68 \pm 0.15 \mathrm{mg}$ $\mathrm{kg}^{-1} \min ^{-1}$ and $1.75 \pm 0.18 \mathrm{mg} \mathrm{kg}^{-1} \mathrm{~min}^{-1}$, respectively). Minimum $R_{\mathrm{a}}$ for HD was $-2.37 \pm 0.26 \mathrm{mg} \mathrm{kg} \mathrm{min}^{-1}$, which was not statistically different to that for NPH or LD. Maximum $R_{\mathrm{d}}$ for HD was $5.21 \pm 0.71 \mathrm{mg} \mathrm{kg}^{-1} \mathrm{~min}^{-1}$, which was significantly greater than with LD $(p<0.03)$. HD appeared to suppress glycerol $R_{\mathrm{a}}$ more than $\mathrm{LD}$, but this difference was not statistically significant. Baseline glycerol was similar to NPH and LD at $1.94 \pm 0.41 \mu \mathrm{mol} \mathrm{kg}{ }^{-1}$ $\mathrm{min}^{-1}$. The maximum change from baseline was $-1.31 \pm$ $0.20 \mu \mathrm{mol} \mathrm{kg}^{-1} \mathrm{~min}^{-1}$ with HD. Baseline NEFA was similar to NPH and LD at $0.52 \pm 0.12 \mu \mathrm{mol} / 1$. The plasma NEFA concentration following HD was significantly lower than with LD (mean difference $-0.20 \mu \mathrm{mol} / 1$; CI -0.32 to -0.09 ; ANOVA, $p<0.01)$.

\section{Discussion}

The equivalence in glucose infusion rate profiles is of key importance when interpreting the comparative effects of two insulin preparations on glucose $R_{\mathrm{a}}$ and glucose $R_{\mathrm{d}}$. Insulin exhibits a different proportion of action at each of these sites at varying concentrations. At low concentrations of insulin, the glucose lowering effect occurs mainly by suppression of glucose $R_{\mathrm{a}}$, with only a small effect on glucose $R_{\mathrm{d}}$. At higher concentrations the majority of action occurs by glucose $R_{\mathrm{d}}$ once glucose $R_{\mathrm{a}}$ has effectively been completely suppressed [20]. Therefore results from studies comparing the effects of two insulin preparations on glucose $R_{\mathrm{a}}$ and $R_{\mathrm{d}}$ under circumstances in which the glucose infusion profile is not equivalent must be treated with caution as differences in effect may be purely related to dose.
Table 2 The effect of low-dose detemir and NPH on glycerol and NEFA metabolism

Values are means \pm SEM

\begin{tabular}{llll}
\hline & Low-dose detemir & NPH insulin & Mean difference (CI) \\
\hline Baseline glycerol $R_{\mathrm{a}}\left(\mu \mathrm{mol} \cdot \mathrm{kg}^{-1} \cdot \mathrm{min}^{-1}\right)$ & $1.75 \pm 0.15$ & $1.91 \pm 0.33$ & 0.17 ( -0.59 to 0.93$)$ \\
Minimum glycerol $R_{\mathrm{a}}\left(\mu \mathrm{mol} \cdot \mathrm{kg}^{-1} \cdot \mathrm{min}^{-1}\right)$ & $0.93 \pm 0.18$ & $0.81 \pm 0.18$ & $-0.11(-0.55$ to 0.33$)$ \\
Mean glycerol $R_{\mathrm{a}}\left(\mu \mathrm{mol} \cdot \mathrm{kg}^{-1} \cdot \mathrm{min}^{-1}\right)$ & $1.39 \pm 0.19$ & $1.24 \pm 0.26$ & $-0.14(-0.79$ to 0.50$)$ \\
Baseline NEFA $(\mathrm{mmol} / \mathrm{l})$ & $0.65 \pm 0.08$ & $0.52 \pm 0.11$ & $-0.13(-0.3$ to 0.4$)$ \\
Minimum NEFA $(\mathrm{mmol} / \mathrm{l})$ & $0.12 \pm 0.04$ & $0.09 \pm 0.03$ & -0.03 (-0.08 to 0.02$)$ \\
Mean NEFA $(\mathrm{mmol} / \mathrm{l})$ & $0.41 \pm 0.06$ & $0.31 \pm 0.05$ & -0.10 ( -0.17 to -0.03$)$ \\
\hline
\end{tabular}


This study was designed to compare relatively low doses. These doses are clinically and physiologically relevant being doses similar to those that might be used as basal insulin replacement. These doses are well below maximum velocity ( $V_{\max }$ ) for glucose $R_{\mathrm{d}}$ and are thus most likely to show differences in glucose $R_{\mathrm{a}}$ and $R_{\mathrm{d}}$, if they exist. We found no difference in total glucose infused to maintain euglycaemia. We also found that the glucose infusion rates for $9 \mathrm{nmol} / \mathrm{kg}$ insulin detemir and $0.3 \mathrm{IU} / \mathrm{kg}$ NPH had an almost identical time-action profile and thus the potency in this study for these two doses was equivalent. Wutte et al. report similar findings in type 1 diabetic patients [21]. The significant differences in the effect of this dose of insulin detemir on glucose $R_{\mathrm{a}}$ and a lesser nonsignificant effect on glucose $R_{\mathrm{d}}$ compared to the equipotent dose of NPH suggests a greater effect on liver than peripheral tissue. Given that we have demonstrated equipotency of these two doses of insulin, these small relative differences are of considerable interest set within the constraints of this metabolic protocol. We hypothesise that the capillary endothelial barrier in adipose tissue and muscle limits the transfer of free insulin detemir from the circulation into the extravascular extracellular space, whereas in the liver, where there is no endothelial barrier, hepatocytes will be exposed to free and bound insulin detemir, possibly allowing greater opportunities for binding of insulin to hepatocyte receptors. Additional support for this hypothesis comes from a novel insulin analogue that binds to thyroid hormone binding proteins and has been shown to have a greater effect on the liver than peripheral tissues [22].

The reduced effect of insulin detemir on peripheral tissues was confirmed by the measurements of NEFA concentrations. Suppression of NEFA concentrations by insulin detemir was less than with an equipotent dose of NPH. There also appeared to be less suppression of glycerol $R_{\mathrm{a}}$ with LD than NPH. However, there was a large inter- and intrasubject variation and statistically significant differences could not be demonstrated. It has been suggested that insulin's suppressive effect on peripheral lipolysis with a decrease in NEFA concentrations is an important signal mediating an indirect effect of insulin on glucose $R_{\mathrm{a}}$ [23] The demonstration in this study that detemir had a greater effect on glucose $R_{\mathrm{a}}$ but a lesser effect on NEFA concentration than an equipotent dose of NPH insulin suggests that the action of detemir on glucose $R_{\mathrm{a}}$ may be independent of NEFA delivery to the liver.

The differential effect of insulin detemir on hepatic and peripheral glucose metabolism suggests that it may be able to partially restore the normal hepatic/peripheral insulin gradient, which may result in several therapeutic advantages. The counter-regulatory hormone response to insulin acts primarily by increasing glucose $R_{\mathrm{a}}$. This is less effective against exogenous insulin, which acts mainly to increase glucose $R_{\mathrm{d}}$. Thus an insulin analogue exerting greater effects on the liver than the periphery has the potential to reduce hypoglycaemic episodes and may reduce weight gain through less snacking to avoid hypoglycaemia. Conversely, it can be argued that an insulin that has a greater effect on $R_{\mathrm{a}}$, would oppose the counter-regu- latory hormones more effectively, and this would exacerbate hypoglycaemia. This however makes less physiological sense as counter-regulatory hormones are likely to overcome effects on hepatic glucose output and are less likely to overcome effects on peripheral glucose uptake.

Peripheral hyperinsulinaemia increases peripheral glucose uptake and lipogenesis and decreases lipolysis, contributing to the weight gain associated with insulin therapy [24]. Kruszynska et al. [9] investigated the effects on carbohydrate metabolism of peripheral insulin delivery compared to portal insulin delivery. They found that hepatic glycogen concentrations are lower in rats receiving insulin into the systemic circulation than in rats receiving insulin via the portal circulation. Others have shown that sensors in the liver to increased intracellular ATP concentrations affect eating behaviour by signals transmitted via vagus afferents from the liver to the brain $[25,26]$. The control of eating behaviour remains a highly complex and controversial subject and many factors have been shown to influence it. Nonetheless, recent large-scale clinical trials comparing detemir and NPH provide support for the theory that by acting in a more physiological way, detemir has advantages over NPH. These trials have shown that nocturnal hypoglycaemic episodes are reduced and weight gain is lower with insulin detemir than with NPH insulin [27-29].

In conclusion, this study suggests that when compared to an equipotent dose of NPH, detemir has a greater effect on glucose metabolism in the liver than in peripheral tissues. This reduced effect of insulin detemir on peripheral tissues was confirmed by the fact that it was less effective in reducing NEFA concentrations than NPH. This suggests that detemir has the potential to restore the physiological insulin gradient, which may have therapeutic advantages such as a lower risk of hypoglycaemia and less weight gain over conventional insulin preparations.

Acknowledgements We are grateful to Nicola Jackson, Mike Stolinski, Premila Croos, William Jefferson, David Lovell and the late Professor Kenneth MacRae for their technical assistance. We would like to thank the Dunhill Medical Trust and Novo Nordisk for financial support. This study received special input from Dr Eberhard Draeger, Lisbeth Jacobson and Dr Lars Endahl at Novo Nordisk.

Duality of interest statement: Professor Russell-Jones has been paid honoraria for lectures by Novo Nordisk, and the study was also funded by Novo Nordisk.

\section{References}

1. Bolli GB (1989) The pharmacokinetic basis of insulin therapy in diabetes mellitus. Diab Res Clin Prac 6:S3-S16

2. Hildebrandt P (1991) Subcutaneous absorption of insulin in insulin dependent diabetic patients: influence of species, physico-chemical properties of insulin and physiological factors. Dan Med Bull 38:337-346

3. Lauritzen T, Faber OK, Binder C (1979) Variation in ${ }^{125} \mathrm{I}$ insulin absorption and blood glucose concentration. Diabetologia 17:291-295

4. Rosskamp RH, Park G (1999) Long acting insulin analogs. Diabetes Care 22:B109-B113 
5. Havelund S, Ribel U, Plum A et al (2004) The mechanism of protraction of insulin detemir, a long acting, acylated analogue of human insulin. Diabetes 53(Suppl):P462

6. Sonksen PH, Russell-Jones D, Jones RH (1993) Growth hormone and diabetes mellitus: a review of sixty-three years of medical research and a glimpse into the future? Horm Res 40:68-79

7. Wurzburger MI, Prelevic GM, Sonksen PH, Wheeler M, BalintPeric L (1995) Effect of recombinant human growth hormone treatment on insulin-like growth factor (IGF-I) levels in insulindependent diabetic patients. Acta Diabetol 32:131-134

8. Janssen JA, Lamberts SW (2000) Circulating IGF-I and its protective role in the pathogenesis of diabetic angiopathy. Clin Endocrinol 52:1-9

9. Kruszynska YT, Home PD, Alberti KGMM (1985) Comparison of portal and peripheral insulin delivery on carbohydrate metabolism in streptozotocin-diabetic rats. Diabetologia 28:167-171

10. Brunner GA, Sendhofer G, Wutte A et al (2000) Pharmacokinetic and pharmacodynamic properties of long-acting insulin analogue NN304 in comparison to NPH in humans. Exp Clin Endocrinol Diabetes 108:100-105

11. Kurtzhals P, Havelund S, Jonassen I et al (1995) Albumin binding of insulins with fatty acids: characterization of the ligand-protein interaction and correlation between binding affinity and timing of the insulin effect in vivo. Biochem J 312: 725-731

12. Ross M, Kaye GI, Pawlina W (2003) Histology a text and atlas. 4th ed. Lippincott Williams and Wilkins, Philadelphia, PA, pp $540-541$

13. Gray H (1973) In: Warwick R, Williams PL (eds) Grays anatomy. 35th ed. Longman, Edinburgh, pp 1308-1309

14. Reichen J (1999) The role of the sinusoidal endothelium in liver function. News Physiol Sci 14:117-121

15. Shojaee-Moradie F, Jackson NC, Jones RH, Mallet AI, Hovorka R, Umpleby AM (1996) Quantitative measurement of 3-O methyl D glucose by gas chromatography mass spectrometry as a measure of glucose transport in vivo. J Mass Spectrom 31:961-966

16. Flakoll PJ, Zheng M, Vaughan S, Borel MJ (2000) Determination of stable isotopic enrichment and concentration of glycerol in plasma via gas chromatography-mass spectrometry for the estimation of lipolysis in vivo. J Chromatogr, B Biomed Sci Appl 744:47-54

17. Heinemann L, Sinha K, Weyer C, Loftager M, Hirsberger S, Heise T (1999) Time-action profile of the soluble fatty acid acylated long-acting insulin analogue NN304. Diabet Med 16: 332-338
18. Steele R, Wall JS, DeBodo RC, Altszuler N (1956) Measurement of size and turnover rate of body glucose pool by isotope dilution method. Am J Physiol 187:15-24

19. Finegood DT, Bergman RN, Vranic M (1987) Estimation of endogenous glucose production during hyperinsulinaemiceuglycaemic glucose clamps: comparison of unlabelled and labelled exogenous glucose infusates. Diabetes 36:914-929

20. Sonksen P, Sonksen J (2000) Insulin: understanding its action in health and disease. Br J Anaesth 85:69-79

21. Wutte A, Plank J, Sinner F et al (2004) Dose-response relationship and within subject variability of insulin detemir and NPH insulin in subjects with type 1 diabetes. Diabetes 53 (Suppl):P638

22. Shojaee-Moradie F, Powrie JK, Sundermann E (2000) Novel hepatoselective insulin analog: studies with a covalently linked thyroxyl-insulin complex in humans. Diabetes Care 23:1124 1129

23. Bergman RN (2000) Non-esterified fatty acids and the liver: why is insulin secreted into the portal vein? Diabetologia 43: 946-952

24. Andreani D (1999) Lights and shadows of insulin treatment seen by a senior diabetologist. Exp Clin Endocrinol Diabetes 107(Suppl 2):S1-S5

25. Mayer J (1991) Bulletin of the New England Medical Center, Volume XIV, April-June 1952: the glucostatic theory of regulation of food intake and the problem of obesity (a review). Nutr Rev 49:46-48

26. Friedman MI (1995) Control of energy intake by energy metabolism. Am J Clin Nutr 62(Suppl 5):1096S-1100S

27. Russell-Jones D, Simpson R, Hylleberg B, Draeger E, Bolinder $\mathrm{J}$ (2004) Effects of QD insulin detemir or neutral protamine Hagedorn on blood glucose control in patients with type I diabetes mellitus using a basal-bolus regimen. Clin Ther 26:724 736

28. de Leeuw I, Vague P, Selam J-L et al (2002) Lower risk of nocturnal hypoglycaemia and favourable weight development in type 1 subjects after 12 months of treatment with insulin detemir vs NPH insulin. Diabetologia 45(Suppl 2):799A

29. Vague P, Selam J-L, Skeie S et al (2003) Insulin detemir is associated with more predictable glycaemic control and lower risk of hypoglycaemia compared to NPH patients with type 1 diabetes on a basal bolus regimen with pre-meal insulin aspart. Diabetes Care 26:590-596 